Journal of Engineering and Applied Sciences 14 (5): 1401-1405, 2019

ISSN: 1816-949X

(C) Medwell Journals, 2019

\title{
A Study on Reasonable Per Person Space for Temporary Housing Facilities
}

\author{
${ }^{1}$ Eun-Ki Hong, ${ }^{1}$ Jong-Hun Han, ${ }^{2}$ Boong-Kyo Seo and ${ }^{1}$ Mi-Jin Park \\ ${ }^{1}$ Division of Architecture and Urban Design, Incheon National University, Incheon, Republic of Korea \\ ${ }^{2}$ Department of Architecture, Gachon University, Gachon, Republic of Korea
}

\begin{abstract}
Due to the effects of urbanization on our modern society, urban areas have become increasingly densely populated. Natural disasters and man-made accidents that occur in societies with such high population densities have resulted in the displacement of large numbers of disaster victims and immense damages following even relatively small-scale disasters. Disaster victims facing such circumstances are exposed to various dangers and can even be subject to secondary physical or psychological harms. This study was undertaken with the goal of finding a means of protecting disaster victims from disasters by establishing the factors necessary to calculate a reasonable per person space within evacuation facilities for victims of disasters, through a study of domestic and overseas cases.
\end{abstract}

Key words: Evacuation facilities, temporary housing, disaster victims, disasters and accidents, psychological harms, displacement

\section{INTRODUCTION}

In recent years, significant human and economic losses due to man-made disasters such as traffic accidents and wars as well as natural disasters such as drought, floods, hurricanes and earthquakes have occurred worldwide. The risks associated with such disasters have been amplified by urbanization and globalization.

The rate of disasters and accidents associated with heavy rainfalls, snowstorms and fires in South Korea have also been on the rise (Table 1).

The Framework Act on the Management of Disasters and Safety stipulates that temporary housing, food and clothing should be provided for emergency relief when people lose their residential space in the event of an accident or disaster. Further details of these stipulations are established in the Anonymous (2015) prepared by the Ministry of Public Administration and Security which state that per person sheltering spaces must in principle, be $3.3 \mathrm{~m}^{2}$ or larger. Despite being established as such in the guidelines, the reasoning applied to the establishment of such spatial areas is lacking.

In light of this, this study aims to propose reasonable per person sheltering spaces in evacuation facilities for disaster victims in the event of disasters and accidents and also aims to identify methods of efficiently utilizing space in evacuation centers for the purpose of providing comfortable living environments for disaster victims.
Table 1: Damages and costs of recovery regarding domestic disasters between $2010 \sim 2015$

\begin{tabular}{lcccccc}
\hline Items & 2010 & 2010 & 2012 & 2013 & 2014 & 2015 \\
\hline Damages & 430,836 & 751,331 & $1,023,320$ & 164,355 & 172,795 & 31,862 \\
Cost of & 722,202 & $1,564,748$ & $1,928,972$ & 369,083 & 486,718 & 38,122 \\
recovery & & & & & & \\
\hline Unit: 1,000 Won
\end{tabular}

\section{Literature review}

Theoretical background

Temporary residential periods and their characteristics: Park (2006) involved the study of the sequence in which residential spaces are to be provided to disaster victims in disaster stricken areas. The sequence involves the provision of temporary sheltering facilities $\rightarrow$ provision of temporary housing spaces $\rightarrow$ permanent recovery. An analysis of each of the steps by period of residence is presented in Table 2.

Temporary sheltering facilities are the most important facilities due to their immediate utilization as a means of protecting the life and physical health of disaster victims through evacuation in the event of a disaster. This is because these facilities are the first evacuation spaces provided to disaster victims capable of minimizing the secondary harm that may occur due to the disaster. However, as a result of the lack of personal space in such temporary shelters due to their purpose of providing only approximately 2 weeks of living quarters for disaster victims, disaster victims residing in such facilities may be subject to psychological and physical harms. For this reason, the study of reasonable per person spaces within temporary sheltering spaces is deemed necessary.

Corresponding Author: Eun-Ki Hong, Division of Architecture and Urban Design, Incheon National University, Incheon, Republic of Korea 
Table 2: Types of temporary housing facilities based on their residential periods

\begin{tabular}{lll}
\hline Types & Residential period & Features \\
Temporary sheltering facilities & Average 2 weeks & $\begin{array}{l}\text { Space where evacuated disaster victims may immediately reside for a temporary period } \\
\text { Makes use of nearby community facilities }\end{array}$ \\
$\begin{array}{l}\text { Temporary housing space } \\
\text { Recovered permanent housing }\end{array}$ & $\begin{array}{l}4-9 \text { months or more } \\
\text { Continued residence following } \\
\text { residence in temporary housing } \\
\text { facilities }\end{array}$ & $\begin{array}{l}\text { Temporary housing facilities created for the purpose of residing for a certain period } \\
\text { Permant housing built in existing residential zones or housing zones for new }\end{array}$ \\
\hline
\end{tabular}

Table 3: Domestic and overseas evacuation center spacing guidelines

\begin{tabular}{|c|c|c|}
\hline Items & Per person space & Features \\
\hline \multicolumn{3}{|l|}{ Domestic } \\
\hline Hurricane and flood disaster & $3.3 \mathrm{~m}^{2}$ & - \\
\hline \multicolumn{3}{|l|}{ Evacuation } \\
\hline \multicolumn{3}{|l|}{ Center } \\
\hline \multicolumn{3}{|l|}{ Designation } \\
\hline \multicolumn{3}{|l|}{ Standards } \\
\hline Earthquake & $3.3 \mathrm{~m}^{2}$ & - \\
\hline \multicolumn{3}{|l|}{$\begin{array}{l}\text { Darisuaster } \\
\text { Disast }\end{array}$} \\
\hline \multicolumn{3}{|l|}{ Evacuation } \\
\hline \multicolumn{3}{|l|}{ Center } \\
\hline \multicolumn{3}{|l|}{ Designation } \\
\hline \multicolumn{3}{|l|}{ Standards } \\
\hline $\begin{array}{l}\text { Guidelines regarding the establishment } \\
\text { of disaster maps }\end{array}$ & $2 \mathrm{~m}^{2}$ & $3.3 \mathrm{~m}^{2}$ for 2 people in the short term, $3.3 \mathrm{~m}^{2}$ for 1 person in the long term \\
\hline Public & $0.825 \mathrm{~m}^{2}$ & Arrange a total of 4 people to fit into a space of $3.3 \mathrm{~m}^{2}$ \\
\hline Evacuation & & Possible application during emergency situations due to extremely crowded space \\
\hline \multicolumn{3}{|r|}{ 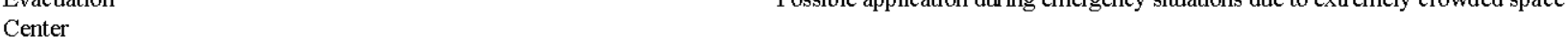 } \\
\hline \multicolumn{3}{|l|}{ Facility } \\
\hline \multicolumn{3}{|l|}{ Designation } \\
\hline \multicolumn{3}{|l|}{ Standards } \\
\hline \multicolumn{3}{|l|}{ Overseas } \\
\hline \multicolumn{3}{|l|}{ USA } \\
\hline Mega & $3.716 \mathrm{~m}^{2}$ & Designation of a 5 feet \\
\hline Shelter & & $\times 8$ feet lay out \\
\hline Planning & & Proposes $6.574 \mathrm{~m}^{2}$ as reasonable space \\
\hline Guide area & & Excludes aisle areas \\
\hline Statewide & $3.716 \mathrm{~m}^{2}$ & Proposes $1.85 \mathrm{~m}^{2}$ in case of emergencies \\
\hline Emergency & & Reasonable spaces are $3.716 \sim 6.574 \mathrm{~m}^{2}$ \\
\hline \multicolumn{3}{|l|}{ Shelter } \\
\hline \multicolumn{3}{|l|}{ Plan } \\
\hline \multicolumn{3}{|l|}{ Japan } \\
\hline Guidelines for shelter management & $1.65 \mathrm{~m}^{2}$ & Space in primary evacuation centers \\
\hline & & Shelter capacities to be flexibly secured in secondary evacuation centers \\
\hline Shelter management in Gifu prefecture & $2 \mathrm{~m}^{2}$ & $\begin{array}{l}\text { Although, } 2 \mathrm{~m}^{2} \text { is the proposed standard, shelter spaces are to be allocated } \\
\text { according to the number of evacuees and the available shelter space }\end{array}$ \\
\hline
\end{tabular}

Analysis of related domestic and overseas guidelines: The per person spaces and characteristics of domestic and overseas evacuation centers are as presented in Table 3.

In domestic guidelines (Anonymous, 2015) in general, the per person space applied in hurricane, flood and earthquake disaster evacuation centers is $3.3 \mathrm{~m}^{2}$ while in public evacuation centers used in emergencies, per person spaces are limited to the extremely crowded space of 4 people per $3.3 \mathrm{~m}^{2}$. Despite such extremely crowded use of space, these spacing plans are considered applicable during the initial phases of a disaster which involve the sheltering of extremely large numbers of disaster victims for short periods. However, the process by which such per person spaces were established was not based on sound reasoning.
In terms of overseas cases, disaster guidelines used in the USA (Anonymous, 2011) and Japan were studied. For the United States, a detailed layout regarding per person spaces was proposed in which reasonable spaces in general were kept separate from reasonable spaces allocated during times of emergencies. In the case of Japan, evacuation centers were operated as primary or secondary evacuation centers, under which secondary evacuation centers operate flexibly based on the number of disaster victims and scale of a disaster.

This study refers to cases in the United States and Japan to discuss the reasons behind the determination of such reasonable spaces and further proposes a detailed length and width layout. This study also separately proposes the spatial areas applied during general circumstances and the spatial areas needed for comfortable living environments. 


\section{MATERIALS AND METHODS}

\section{Considerations regarding the proposal of a reasonable space}

Architectural module: The purpose of this study is to calculate appropriate indoor spatial areas which involves the selection of an appropriate module to be applied in indoor areas. In general, in architecture, horizontal module plans extend the dimension of a horizontal module by $300 \mathrm{~mm}(3 \mathrm{M})$ and vertical module plans extend the dimension of a vertical module by $100 \mathrm{~mm}$ (1M) as their measurement increments. School gymnasiums, considered common indoor temporary housing spaces are also configured along such modules.

Shin and Han (2004) undertook studies regarding the architectural planning of multi-purpose school facilities such as indoor gymnasiums. The results of the study indicated that most gymnasium floor plans are configured to enable various events and performances in the direction of its length include large stages and are equipped with equipment storage facilities, work spaces and dressing rooms along its rear areas. In addition, most gymnasiums are configured to house standard basketball courts across an area of $25 \times 32 \mathrm{~m}$. Also, due to the module having to consider spaces not only for basketball courts and volleyball courts but also a variety of other spatial accommodations, the symmetrical shape and function of an area capable of accommodating a single basketball court was taken into consideration which resulted in the finding that planning in 3,4.5 and $6 \mathrm{~m}$ intervals was most efficient in such structures when accounting for the length of columns. This is consistent with the general $3 \mathrm{M}$ horizontal module used in architecture.

Size of blankets: Under the disaster relief planning guidelines, temporary housing spaces, food and daily necessities must be provided to disaster victims. Blankets are included among the list of items provided as daily necessities. Also, blankets are included in disaster relief items packages stored by the national association for disaster relief and distributed to victims in the event of a disaster for the purpose of immediate and efficient disaster relief (Fig. 1).

In the event of the evacuation of disaster victims due to disasters or accidents, mattresses and beds typically cannot be adequately supplied. The immediate and quick distribution of blankets in evacuation facilities that are conveniently stored during normal times is considered the most efficient method.

The dimensions of such blankets are $2,000 \times 1,500 \mathrm{~mm}$. Considering that the international standard size of blankets used during camping is typically $2,000 \sim 2,100 \times$

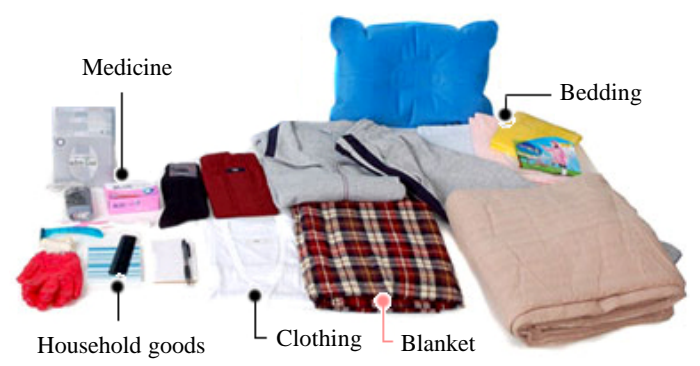

Fig. 1: Disaster relief item package
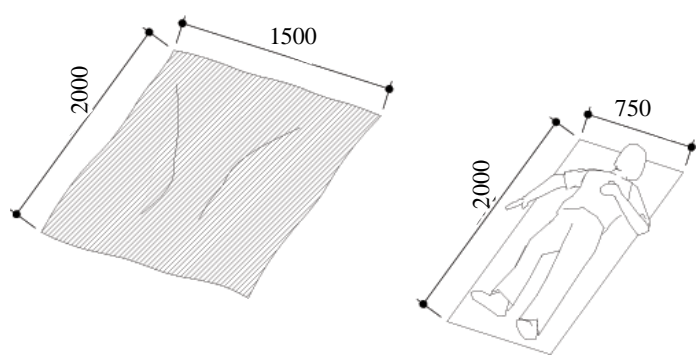

Fig. 2: Size of blankets

$1,400 \sim 1,500 \mathrm{~mm}$, the above dimensions can be considered a common size. By folding this blanket in half, the size is reduced to approximately $700 \sim 750 \mathrm{~mm}$ in width which is slightly longer than the average shoulder width of an adult male at approximately $600 \mathrm{~mm}$ and is therefore, appropriate for the sleeping space of 1 person (Fig. 2).

Free space: Living quarters within an evacuation center can be classified into sleeping spaces and non-sleeping spaces. Sleeping spaces are usually left empty for bedding, however, non-sleeping spaces are typically used as space for storing materials that are provided from the evacuation center such as personal items and others (Kim et al., 2011).

Nevertheless, the per person space of most evacuation facilities as shown in Fig. 3 indicates that there is difficulty in securing adequate sleeping spaces when additional areas for laundry and bedding items are needed during extended evacuation periods. Because of this, free space that can sufficiently accommodate the placement of such items is needed (Gyeong-Suk and Min-Gyeong, 2011).

\section{Proposal of a reasonable per person space}

The process of establishing a reasonable per person space: Referring to existing studies and their implications, disaster victims spend a maximum of 2 weeks in evacuation facilities. During this time, the disaster victims require not only sleeping space but also non-sleeping space or free space where they can store basic items and engage in basic activities. In consideration of 


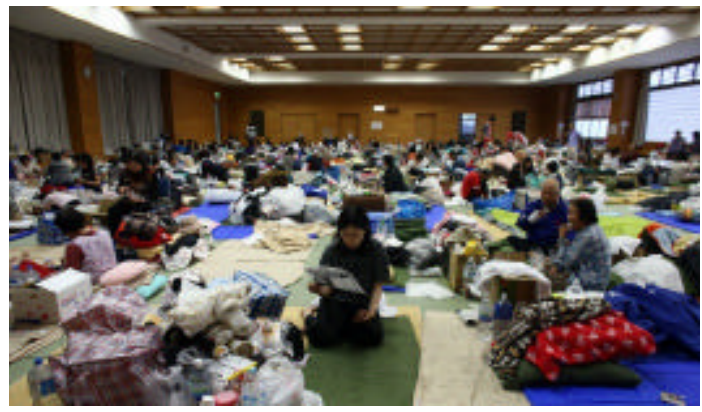

Fig. 3: Overview of a Japanese evacuation facility

this, the process of establishing an appropriate per person space was undertaken through the following steps.

First, the space must satisfy minimal needs for sleeping spaces. In consideration of typical mattress sizes or hospital beds, this space must be $1,000 \times 2,000 \mathrm{~mm}$ or larger. Second, a living space that is larger than the dimensions of the supplied disaster relief blanket $(1,500 \times 2,000 \mathrm{~mm})$ must be provided. Third, the space must be adjusted to satisfy the $3 \mathrm{M}$ architectural module. Fourth, a space that appropriately establishes expandability in the direction of widths and lengths that also includes free space must be provided. The reasonable space established through the above process is presented in Table 4.

Review of the space: A comparison of the A and B types proposed in this study indicates that the expansion in the width direction of type A results in the establishment of relatively large free spaces within each allocated space, securing a relatively comfortable living environment capable of accommodating various activities.

Expansion in the length direction as in the case of type $B$ resulted in the establishment some free space at the bottom of each allocated space for the storage of relief items and personal belongings and also resulted in a relatively narrow and confined space.

The findings of this study indicate that type $\mathrm{A}$ should be applied in evacuation centers that have a degree of spatial leeway and need relatively comfortable living environments for disaster victims and that type $B$ should be applied in evacuation centers where efficient allocation of space is needed due to a lack of space.

Through the flexible application of either of the two proposed spaces in evacuation centers sheltering disaster victims, a clear layout in terms of the efficient allocation of space for disaster victims within an evacuation center is expected to be enabled.

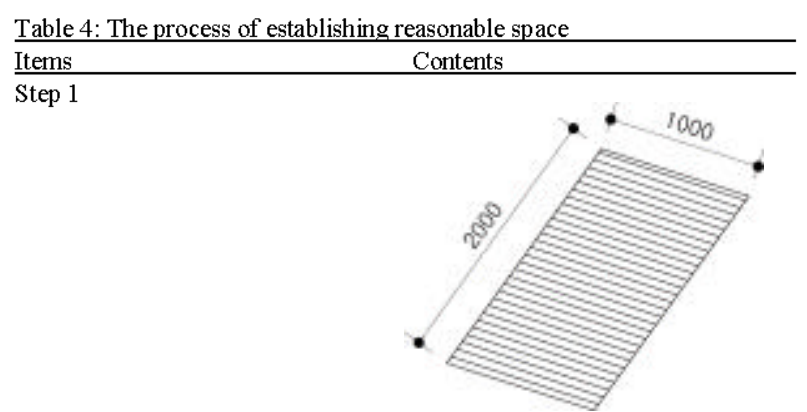

Step 2

Secure sleeping area $\left(2 \mathrm{~m}^{2}\right)$

Step 3

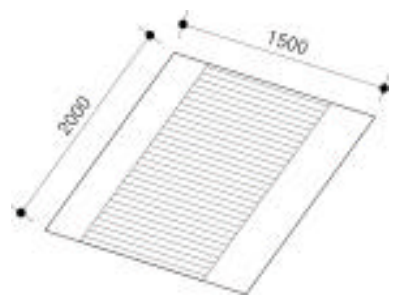

Secure blanket area $\left(3 \mathrm{~m}^{2}\right)$

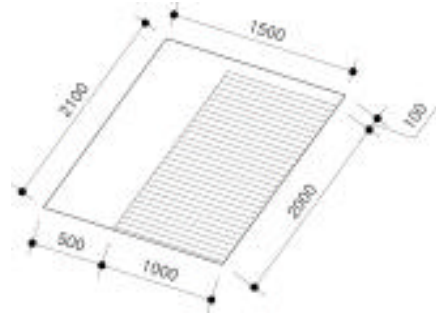

Apply construction module $\left(3.15 \mathrm{~m}^{2}\right)$

Proposed space

A type

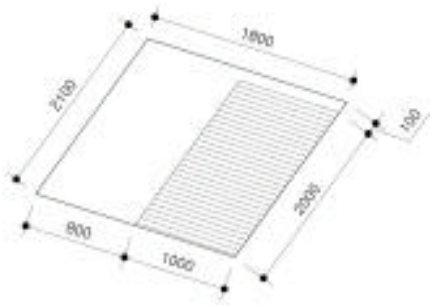

Width direction expansion $\left(3.78 \mathrm{~m}^{2}\right)$

Proposed space

B type

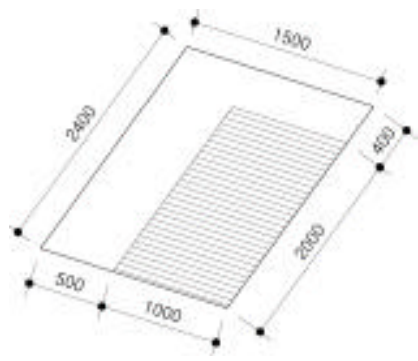

Length direction expansion $\left(3.60 \mathrm{~m}^{2}\right)$

\section{RESULTS AND DISCUSSION}

This study established a reasonable spatial area per person based on the following considerations; First, a 
reasonable spatial area must provide adequate sleeping space and thus should be at least $1,000 \times 2,000 \mathrm{~mm}$ in size. Second, the spatial area must be $1,500 \times 2,000 \mathrm{~mm}$ or larger which is the typical size of the blankets provided in the event of a disaster. Third, the spatial area must satisfy the $3 \mathrm{M}$ architectural module. Fourth, the spatial area must include free space in addition to the sleeping space.

With the changing climate and the increased frequency of abnormal weather, disasters and accidents have been occurring more regularly. In densely populated urban areas, the occurrence of natural disasters as well as man-made disasters associated with fire or terrorist activities may result in devastating harm to property and human lives. Given such circumstances, although, evacuation facilities capable of sheltering and safely protecting disaster victims are being provided, a sound basis for standards on the allocation of space for disaster victims within such evacuation facilities is currently lacking. In consideration of this, this study was undertaken for purpose of finding and proposing a reasonable spatial area to be provided to each disaster victim sheltered in an evacuation facility in the event of disasters and accidents.

\section{CONCLUSION}

The reasonable per person space determined through this process included a $3,78 \mathrm{~m}^{2}$ sized layout having a width of $1,800 \mathrm{~mm}$ and length of $2,100 \mathrm{~mm}$ and a $3,60 \mathrm{~m}^{2}$ sized layout having a width of $1,500 \mathrm{~mm}$ and length of $2,400 \mathrm{~mm}$. This is an area that can accommodate sleeping spaces at the size of the distributed blankets while also providing sufficient free space for storing personal items, daily necessities and performing activities such as changing clothes, arranging bedding and taking one's shoes off. This also meets the requirement of the $3 \mathrm{M}$ architectural module and is suitable for indoor spaces. Also, either of the two modules may be applied flexibly to evacuation centers of varying sizes as well as to different cases of accommodating varying numbers of disaster victims.

\section{LIMITATIONS}

This study is limited in that it does not account for space needed for privacy considerations as well as the space needed for individuals to travel within the evacuation centers.

\section{RECOMMENDATION}

Further studies that account for such factors are deemed to be necessary.

\section{ACKNOWLEDGEMENT}

This research was supported by a Grant (17CTAPC115046-02) from Technology Advancement Research Program (TARP) funded by Ministry of Land, Infrastructure and Transport of Korean Government.

\section{REFERENCES}

Anonymous, 2011. Commonly used sheltering items and services listing (CUSI-SL). Federal Emergency Management Agency, Washington, D.C., USA.

Anonymous, 2015. Disaster relief planning guidelines. Ministry of Public Safety and Security, South Korea.

Gyeong-Suk, K. and K. Min-Gyeong, 2011. The school design factors as emergency shelter after disaster-focus on the function for evacuation center and education maintenance. J. Korean Inst. Educ. Facilities, 18: 75-82.

Kim, M.G., H. Moon, H.J. Kim and K.S. Kim, 2011. A study on the residential planning factors for emergency shelter after disaster. J. Archit. Inst. Korea, 27: 93-102.

Park, Y.J., 2006. A study on the measures of the residence stabilization for the dwellers in the disaster areas. Ph.D Thesis, Department of Real Estate Graduate School, Kangwon National University, Chuncheon, South Korea.

Shin, W.S. and K.Y. Han, 2004. The study about architectural plan and practical use of multipurpose room of school facilities (Auditorium, Gymnasium). J. Korean Inst. Educ. Facilities, 11: 5-16. 